\title{
Suppression of circulating lgD+CD27+ memory B cells in infants living in a malaria-endemic region of Kenya
}

\author{
Amolo S Asito ${ }^{1,2^{*}}$, Erwan Piriou ${ }^{2,3,4}$, Walter GZO Jura ${ }^{1}$, Collins Ouma ${ }^{1,2}$, Peter S Odada ${ }^{2}$, Sidney Ogola ${ }^{1,2}$, \\ Nancy Fiore ${ }^{3}$ and Rosemary Rochford ${ }^{3^{*}}$
}

\begin{abstract}
Background: Plasmodium falciparum infection leads to alterations in B cell subset distribution. During infancy, development of peripheral B cell subsets is also occurring. However, it is unknown if infants living a malaria endemic region have alterations in $B$ cell subsets that is independent of an age effect.

Methods: To evaluate the impact of exposure to P. falciparum on B cell development in infants, flow cytometry was used to analyse the distribution and phenotypic characteristic of B cell subsets in infant cohorts prospectively followed at 12, 18 and 24 months from two geographically proximate regions in western Kenya with divergent malaria exposure i.e. Kisumu (malaria-endemic, $n=24$ ) and Nandi (unstable malaria transmission, $n=21$ ).

Results: There was significantly higher frequency and absolute cell numbers of CD19+ B cells in Kisumu relative to Nandi at $12(p=0.0440), 18(p=0.0210)$ and 24 months $(p=0.0493)$. No differences were observed between the infants from the two sites in frequencies of naïve B cells (lgD+CD27-) or classical memory B cells (IgD-CD27+). However, immature transitional B cells (CD19+CD10+CD34-) were higher in Kisumu relative to Nandi at all three ages. In contrast, the levels of non-class switched memory B cells (CD19+lgD+CD27+) were significantly lower overall in Kisumu relative to Nandi at significantly at $12(p=0.0144), 18(p=0.0013)$ and 24 months $(p=0.0129)$.

Conclusions: These data suggest that infants living in malaria endemic regions have altered $B$ cell subset distribution. Further studies are needed to understand the functional significance of these changes and long-term impact on ability of these infants to develop antibody responses to $P$. falciparum and heterologous infections.
\end{abstract}

Keywords: B cells, Infant immunity, Plasmodium falciparum

\section{Background}

Development of immunity is dependent on both exposures to pathogens as well as age of the host. Children living in malaria endemic regions of sub-Saharan Africa have the burden of both early age of exposure and repeated exposure to malaria while their immune system is developing. That this is problematic is evidenced by the fact that not only do children under 5 years of age suffer the highest morbidity and mortality due to Plasmodium falciparum infection, they also have the highest all-cause mortality of any age group living in malaria endemic regions. Several

\footnotetext{
*Correspondence: Jakogwanjo@gmail.com; rochforr@upstate.edu 1 Maseno University, Maseno, Kenya

${ }^{3}$ SUNY Upstate Medical University, Syracuse, NY, USA

Full list of author information is available at the end of the article
}

reasons have been proposed, however, it is generally agreed that this phenomenon is likely due to inefficient innate and adaptive immune responses and/or immunopathology that ensue due to disease [1-3].

During childhood, there are a number of changes in the lymphocyte compartment and these are especially evident in the period from birth through 2 years of age. Infants have significantly higher numbers of peripheral CD19+ B cells as compared to adults. And while development of germinal centres and memory B cells can occur soon after birth, the relative percentage of memory B cell expands over time and reflects the infants' antigenic history. Of note as well, is the inability of infants to respond to $\mathrm{T}$ independent antigens until $\sim 2$ years of age. Marginal zone B cells in infants express the enzyme 
activation induced deaminase (AID) essential for somatic hypermutation but in adults, these same cell types do not express AID [4]. The peripheral equivalent of the marginal zone cell is the IgM+IgD+CD27+CD19+ non-class switched memory B cell. These cells have been shown to have a diversity of immunoglobulin receptors with evidence of somatic hypermutation but are thought to be independent of germinal center passage [5]. This cell type increases from infancy and reaches adults values by 2-3 years of age where it composes approximated 5-10\% of the total B cell compartment similar to the percentages observed for classical memory B cells (IgM-IgD-CD27 +CD19+)[4]. Interestingly, splenic non-class switched IgD $+\mathrm{CD} 27+\mathrm{B}$ cells are thought to be essential for rapid mobilization to blood borne pathogens as well as Streptococcus pneumonia [6]. The rapid mobilization is more typical of innate immune response than adaptive immunity and thought to emerge from TLR9 signalling of transitional B cells [7].

Chronic infections such as HIV and hepatitis $C$ virus have been shown to perturb the distribution of peripheral B cell subsets. While P. falciparum is not a chronic infection per se, in infants, repeated exposures and delay of clearance of the pathogen is likely to make the host respond to $P$. falciparum more like a chronic infection. This is evidenced by the similarities in altered B cell subpopulations observed during malaria and HIV infections. For example, in both HIV and P. falciparum infected hosts, increases in transitional CD19+CD10+ B cells [8,9], decrease in IgD-CD27+ memory B cells [9-12], and increases in $\mathrm{CD} 21^{\text {lo }}$ atypical exhausted B cells $[8,11]$ have been reported. Children infected with HIV were found to have a selective depletion of non-class-switched (IgD $+\mathrm{CD} 27+$ ) memory B cells relative to healthy children [13]. A recent study in a mouse model of Plasmodium showed selective depletion of marginal zone B cells during acute Plasmodium chabaudi infection [14], but it is unknown if this also occurs in humans.

Given that memory B cell lineages are established during infancy and P. falciparum infections perturb memory B cells populations critical in the elaboration of effective humoral immune responses $[9,11]$, there is a need for a better understanding of the effect of early exposure to $P$. falciparum infection on infant B cell development. In this study, peripheral B cell subsets were characterized in a longitudinal cohort of infants followed through 2 years of age. Infants were enrolled from two regions of Western Kenya that experience different patterns of malaria transmission intensity throughout the year, thus allowing us to ask how increasing $P$. falciparum transmission affected development of B cell compartments independent of agerelated changes in the $B$ cell compartment that occur through this period.

\section{Methods}

\section{Study site and population}

The study was performed using the infrastructure of two sub-district hospitals that serve rural populations: Chulaimbo sub-district hospital, in Kisumu county (a malaria holoendemic region), where residents receive 100300 infective mosquito bites per annum and $P$. falciparum accounts for $97 \%$ of the malarial infections primarily in infants [2,15], and Mosoriot sub-district hospital in Nandi county, an area that experiences unstable malaria transmission with an estimated entomological inoculation rate of 12 infective mosquito bites per annum [16,17].

The samples used for this study were from a larger study [18] and only those participants with enough remaining peripheral blood mononuclear cells (PBMCs) for B cell immunophenotyping were included in this study. Approval of this study was obtained from both the Kenya Medical Research Institute and SUNY Upstate Medical University Ethical Review Boards. Written informed consent was obtained from the parents or guardians of study participants before any sample collection. The enrolment criteria involved recruiting pregnant women who were HIV-negative from the two study sites and following their children from 1 month of age up through 24 months. All infants were enrolled in a three-month period, from April 2006-June 2006. As part of the study participant's health care, the infants were closely monitored for any illness and all cases were reported to the study clinicians for treatment as per Kenya Ministry of Health $(\mathrm{MOH})$ guidelines. A total of 38 children from Chulaimbo sub-district hospital in Kisumu county (herein referred to as Kisumu) and 36 from Mosoriot sub-district hospital in Nandi county (herein referred to as Nandi) had PBMC collected at 12, 18 and 24 months for B cell immunophenotyping analysis. At the end of 24 months follow-up there were 24 infants from Kisumu and 21 from Nandi who were captured during the three time points and all subsequent analyses were based on these sample sizes.

\section{Blood collection and processing}

Finger-prick blood was collected in EDTA tubes and measurements of haemoglobin $(\mathrm{Hb})$ levels were determined using a portable $\beta$-haemoglobin photometer (Hemocue AB Angelholm, Sweden), white complete blood counts were performed with a Beckman Coulter AcT diff2 (Beckman-Coulter Corporation, Miami, FL, USA). In addition, 1-3 $\mathrm{ml}$ of venous blood from the study participants into heparinized vacutainer tubes. Samples were collected at the same period of time for both sites and in any given week when infants were 12, 18 and 24 months of age, samples from infants of the appropriate age from both Kisumu and Nandi were collected and analysed. Ficoll density gradient centrifugation of blood 
was done within $1 \mathrm{~h}$ of blood collection; the plasma was removed for subsequent serologic analysis. PBMCs were analyzed immediately for immunophenotype analysis.

\section{Quantitative PCR investigation of $P$. falciparum parasites}

Due to the fact that microscopy has been shown to underestimate the frequency of $P$. falciparum infection in asymptomatic individuals from areas with unstable malaria transmission [19], both thin/thick smear Giemsa staining as well as Q-PCR on DNA extracted from peripheral blood by quantitative PCR was performed as described [18].

\section{Peripheral blood mononuclear cell isolation and cell surface phenotyping}

The frequencies of B cell sub-populations in PBMCs were analysed by flow cytometry and data acquired using FACScalibur (Becton Dickinson Immunocytometry Systems, San Jose, USA). The following monoclonal antibody (mAb) panels were used: pan-lymphocyte panel (antiCD45-APC, anti-CD19-PE, anti-CD3-FITC), T cell panel (anti-CD3-APC, anti-CD8-FITC, anti-CD4-PE), B cell subset panel (anti-IgD-FITC, anti-CD27-PE, anti-CD19-APC) and transitional B cell panel (anti-IgD-FITC, anti0CD10$\mathrm{PE}$, anti-CD19-APC). Isotypic controls were $\operatorname{IgG}_{2 \mathrm{a}}, \mathrm{K}$ -FITC (mouse), IgG 1 , K-PE (mouse) and IgG 1 , K-FITC (mouse) (BD Pharmingen, San Diego, CA, USA). For the B cell subset analysis, a minimum of 10,000 gated $\mathrm{CD} 19^{+}$ lymphocytes were acquired; for the pan-lymphocyte and $\mathrm{T}$ cell subsets, a minimum of 10,000 lymphocytes based on FSC/SSC were acquired. Absolute cell counts for lymphocyte subsets were based on white blood cell counts obtained on each sample. All flow cytometry data were processed using FlowJo software (Tree Star Inc., San Carlos, CA, USA).

\section{Statistical methods}

GraphPad Prism version 5 (GraphPad Software, Inc, La Jolla, CA, USA) was used for statistical analysis. Statistical difference in categorical variables between the two defined groups was determined using Fischer exact test while Mann-Whitney U test was used to determine differences in continuous variables. Age-related change in the lymphocyte populations and Ig levels were evaluated using Friedman test with post-hoc Dunns test for multiple comparisons. Correlation was done using non-parametric Spearman analysis. doing $P$ values of $\leq 0.05$ were considered statistically significant.

\section{Results}

Demographic and clinical characteristics of the study population

To follow infants with divergent underlying exposure to malaria, we recruited infants from two rural study sites in Western Kenya. The first site was in Nyanza Province,
Kisumu District. This area experiences endemic malaria and is characterized by intense, perennial transmission [20]. The second study site was in the highlands of Rift Valley Province, Nandi District, where malaria transmission is unstable and associated with periodic outbreaks of malaria morbidity [20]. Infants were enrolled at 1 month of age, and blood samples were collected monthly through the first year and then every 3 months through two years. Venous blood draws were done at 12, 18 and 24 months. To confirm previously reported differences in malaria exposure between these two sites [20,21], the DNA samples from each cohort were analysed for $P$. falciparum DNA by Q-PCR. A significantly higher number of children with asymptomatic $P$. falciparum parasitaemia was found in the Kisumu children at any given time and higher malaria parasitaemia for children from Kisumu relative to Nandi [18]. At the time of venous blood draws, none of the infants were positive for P. falciparum by blood smear and all had temperatures within the normal range (Table 1 ). However, $P$. falciparum DNA was detected in both Kisumu and Nandi infants using the more sensitive Q-PCR method [22]. The proportions of infants that were positive for P. falciparum by Q-PCR were significantly higher in Kisumu relative to Nandi at $12(p=0.0331)$ and 24 months $(p=0.0025)$, while they were comparable at 18 months $(p=0.7351)$. In addition, age-related analysis revealed significantly higher parasitaemic infants at 12 months relative 18 and 24 months in both cohorts (both, $p<0.0001$ ).

\section{Infants from Kisumu have elevated frequency of total CD19 ${ }^{+} \mathrm{B}$ cells}

To evaluate the impact of early exposure to differential $P$. falciparum transmission on infants lymphocyte subsets, freshly isolated PBMCs from Kisumu and Nandi infants were stained with anti-CD45, anti-CD3 and anti-CD19 $\mathrm{mAB}$ and analysed by multicolor flow cytometry to identify $\mathrm{CD} 45^{+} \mathrm{CD}^{+} \mathrm{T}$ and $\mathrm{CD} 45^{+} \mathrm{CD} 19^{+} \mathrm{B}$ cell subsets at 12 , 18 and 24 months of age. Percentages and absolute numbers of each subset are shown in Figure 1. Infants from Kisumu had significantly higher percentages of CD $19^{+} \mathrm{B}$ cells relative to Nandi at $12(p=0.0440), 18(p=0.0210)$ and 24 months $(p=0.0493)$. In addition, Kisumu infants also had significantly higher absolute numbers of CD19 $9^{+} \mathrm{B}$ cells relative to Nandi infants at 12 and 24 months indicating that percentage increases in $\mathrm{CD} 19^{+}$cells were not due to changes in the $\mathrm{T}$ cell subset. Consistent with previous reports $[23,24]$, there was no age-related change in the frequency of CD19+ B cells in both cohorts.

To further examine $T$ cell subsets, the percentages of $\mathrm{CD}^{+} \mathrm{CD}^{+}$and $\mathrm{CD}^{+}{ }^{+} \mathrm{CD} 8^{+} \mathrm{T}$ cells was done by staining with anti-CD3, -CD4 and -CD8 mABs. Strikingly, the frequency of CD4 $\mathrm{T}$ cell and CD4/CD8 $\mathrm{T}$ cell ratio were significantly higher in Nandi relative to Kisumu at 12 months 
Table 1 Demographic, parasitological and hematological characteristics of the study population

\begin{tabular}{|c|c|c|c|c|c|c|c|c|}
\hline \multirow[b]{2}{*}{ Parameter } & \multicolumn{4}{|l|}{ Kisumu } & \multicolumn{4}{|l|}{ Nandi } \\
\hline & 12 months & 18 months & 24 months & $p$-value & 12 months & 18 months & 24 months & $p$-value \\
\hline No. of participants & 24 & 24 & 24 & & 21 & 21 & 21 & \\
\hline \multicolumn{9}{|l|}{ Gender } \\
\hline Male (n[\%]) & $14(58)$ & $14(58)$ & $14(58)$ & & $9(43)$ & $9(43)$ & $9(43)$ & \\
\hline P. falciparum BS+ & 0 & 0 & 0 & & 0 & 0 & 0 & \\
\hline P.falciparum Q-PCR+ (n[\%])* & $13(54)$ & $5(21)$ & $8(33)$ & $<0.0001^{\mathrm{a}}$ & $8(38)$ & $5(24)$ & $3(14)$ & $<0.0001^{\mathrm{a}}$ \\
\hline Temperature ${ }^{\circ} \mathrm{C}$ & $36.55(0.008)$ & $36.51(0.48)$ & $36.27(0.12)$ & & $36.64((0.34)$ & $36.58(0.4)$ & $36.74(0.1)$ & \\
\hline \multicolumn{9}{|l|}{ Erythrocyte indices } \\
\hline $\mathrm{Hb}$ conc $(\mathrm{g} / \mathrm{dl})$ & $10.85(0.25)$ & $11.07(0.26)$ & $11.50(0.26)$ & $0.0390^{\mathrm{b}}$ & $11.21(0.26)$ & $11.37(0.28)$ & $11.76(0.34)$ & $0.0524^{\mathrm{b}}$ \\
\hline $\operatorname{RBCs}\left(10^{6} / \mu \mathrm{l}\right)$ & $5.00(0.07)$ & $4.90(0.14)$ & $4.68(0.09)$ & $0.0191^{\mathrm{b}}$ & $4.73(0.01)$ & $5.03(0.08)$ & $4.77(0.01)$ & $0.0019^{b}$ \\
\hline
\end{tabular}

Data presented as Mean (SEM) unless otherwise stated

Abbreviations: $\mathrm{Hb}$ conc hemoglobin concentration; RBCs red blood cells. Statistically significant $p \leq 0.05$ are in bold

${ }^{a}$ The differences in proportions over the three time points was determined using Fischer exact test

${ }^{b}$ Analysis of the continuous variables over the three time points was determined by Friedman test with post-hoc Dunns test for multiple comparisons

*Parasitemic infants were significantly higher in Kisumu relative to Nandi at $12(p=0.0331), 18(p=0.7351)$ and 24 months $(p=0.0025)$

of age ( $p=0.0294$ and $p=0.041$, respectively) (Table 2$)$. However, no significant differences were observed at other time points. When we analysed whether there were agedependent changes in $\mathrm{T}$ cell subsets, no significant differences were observed.

\section{Expanded populations of immature transitional B cells in} infants from a malaria-endemic region

Expansion of the immature transitional CD $10^{+} \mathrm{CD} 34-\mathrm{B}$ cell population is observed during acute clinical P. falciparum malaria, HIV infection and in autoimmune diseases $[9,25]$. However, these studies have only been performed in adults and children above 2 years of age. To determine if there were differences in the frequency of immature transitional cells in our cohort, PBMCs were analysed for the presence immature transitional $B$ cells. The frequency of immature transitional B cells (CD19+CD10+CD34-) was expanded in Kisumu relative to Nandi at all three times points although only significantly higher in Kisumu at 12 $(p=0.0233)$ and 24 months of age $(p=0.0338)$. However, no significant age-related change in the frequency of this subset was observed in both cohorts (Figure 2a).

\section{Suppressed levels of (IgD+CD27+) non class-switched} memory $B$ cells in infants from malaria-endemic region Viral and bacterial infections in paediatric populations are associated with depletion of non-class-switched memory B cells $[5,11,13,26]$. However, whether there is diminution of this subset in infants living in areas with high intensity of $P$. falciparum transmission has not been analysed. Moreover, there are no studies that directly address age-related changes in the frequency of this population in infants. To analyse the effects of age and $P$. falciparum transmission on development of B cell subsets, PBMCs were stained with $\mathrm{CD} 19$, IgD and CD27 mABs to discriminate naive (IgD+CD27-) from three memory B cell subsets; classical
$(\mathrm{IgD}-\mathrm{CD} 27+)$, non class-switched $(\mathrm{IgD}+\mathrm{CD} 27+)$ and IgDCD27-. This latter subset is a heterogeneous subset that contains both transitional (IgD-CD10+) and atypical memory (IgD-CD27-) B cells (Figure 3). Because only threecolor flow cytometry analysis was available, it was not possible to further distinguish between these two populations.

As expected, naive CD19+IgD+CD27- B cells were the predominant population in both cohorts and at all time points (Figure. $2 \mathrm{~b}$ ). The percentages decreased over time. Concomitantly, significant age-related increases in the frequency of in classical memory CD19+IgD-CD27 in both cohorts $(p<0.0001)$ were observed (Figure $2 c)$. With the exception of a slightly but significantly higher percentage of CD19+IgD-CD27+ B cells at 12 months of age in the Kisumu infants relative to the Nandi infants $(p=0.049)$, no other differences between the cohorts were noted. Multiple comparisons test revealed a significant age-related change in the frequency of this subset in both cohorts $(p<$ 0.0001 ). Interestingly, when comparison was made in the percentage of cells that were IgD $+C D 27+$, a reduced population of $\mathrm{IgD}^{+} \mathrm{CD} 27^{+} \mathrm{B}$ cells was observed in Kisumu relative to Nandi at 12,18 and 24 months $(p=0.0144, p=$ 0.0013 and $p=0.0129$, respectively) (Figure $2 \mathrm{~d}$ ). Moreover, there was a significant age-related increase in the proportion of this subset in both cohorts (both, $p<0.0001$ ). These data also revealed elevated frequency of CD19+IgD$\mathrm{CD} 27-\mathrm{B}$ in Kisumu at 18 months $(p=0.0278)$ relative to Nandi. While multiple comparison analysis revealed no significant age-related change in the Nandi cohort ( $p=$ 0.6618 ), there was a significant increase in Kisumu cohort over time $(p<0.0008)$, with post-hoc analysis revealing lower percentages at 12 months relative to 18 and 24 months (all, $p<0.05$, after a Dunns test for multiple comparisons) (Figure 2e). A summary of absolute B cell counts and the differences among the groups analysed is also shown in Additional file 1. 


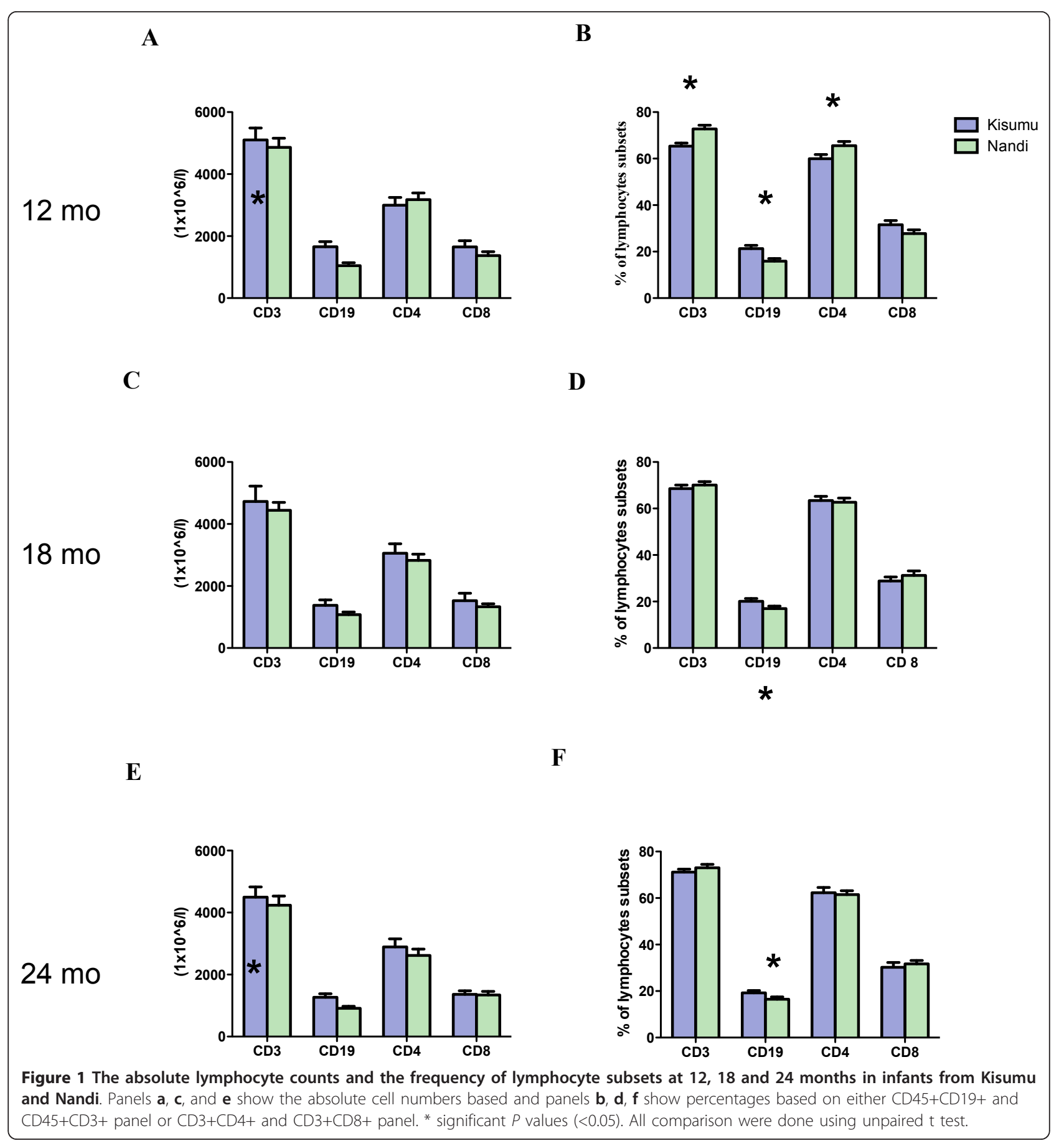

While none of the infants in the study at the time of sample collection had evidence of clinical malaria which would be indicated by fever greater than $37.5^{\circ} \mathrm{C}$ and detectable parasites on peripheral blood smear greater than 5000 (all were blood smear negative), there were infants that were $P$. falciparum positive based on detection of parasite DNA by Q-PCR. To determine if there was an impact of being $P$. falciparum DNA positive on different frequencies of CD19+ B cells, IgD+CD27+ B cell subset and the CD10
+CD34- B cell subset, we did a Spearman correlation and found that being $P$. falciparum DNA positive did not correlate with increased or decreased frequencies of IgD +CD27+ B cell subset and the CD10+CD34- B cells.

\section{Discussion}

Impaired humoral immune protection associated with prenatal or chronic exposure to $P$. falciparum is a common immunological abnormality in paediatric populations from 
Table 2 Comparative flow cytometric analysis of peripheral lymphocytes distribution in infants from Kisumu and Nandi

\begin{tabular}{lllllllll}
\hline \multirow{2}{*}{ Parameter } & Kisumu & \multicolumn{7}{l}{ Nandi } \\
\cline { 2 - 8 } CD45+CD19+ B & $\mathbf{1 2}$ months & $\mathbf{1 8}$ months & $\mathbf{2 4}$ months & $\boldsymbol{p}$-value & $\mathbf{1 2}$ months & $\mathbf{1 8}$ months & $\mathbf{2 4}$ months & $\boldsymbol{p}$-value \\
\cline { 2 - 8 } cells & 17.55 & 18.93 & 19.61 & 0.4233 & 14.80 & 15.81 & 15.77 & 0.8372 \\
CD45+CD3+ T & $(15.03-28.35)$ & $(17.05-24.41)$ & $(15.23-22.44)$ & & $(10.65-21.45)$ & $(11.72-19.02)$ & $(12.79-18.95)$ & \\
cells & 66.35 & 66.94 & 69.62 & 0.0768 & 73.80 & 74.44 & 71.79 & 0.9995 \\
CD3+CD4+ T & $(59.23-70.35)$ & $(62.42-73.87)$ & $(66.15-75.10)$ & & $(67.70-79.45)$ & $(68.56-76.79)$ & $(69.47-77.74)$ \\
cells & 58.30 & 63.72 & 65.12 & 0.2275 & 70.40 & 62.31 & 61.53 & 0.1315 \\
CD3+CD8+ T & $(54.15-67.10)$ & $(58.19-70.84)$ & $(49.09-72.07)$ & & $(60.50-74.50)$ & $(57.26-72.63)$ & $(53.97-67.18)$ & \\
cells & 32.70 & 25.81 & 26.33 & 0.1684 & 24.40 & 27.06 & 31.20 & 0.2144 \\
CD4/CD8 ratio & $(23.85-36.75)$ & $(21.99-34.05)$ & $(21.58-44.75)$ & & $(19.75-31.65)$ & $(22.06-35.69)$ & $(25.53-33.70)$ & \\
\end{tabular}

Freshly isolated PBMCs from Kisumu $(n=24)$ and Nandi $(n=21)$ infants were analyzed by multicolor flow cytometry following staining with various combinations of monoclonal antibodies $(\mathrm{mAB})$. The data are presented as median $\left(25^{\text {th }}-75^{\text {th }}\right.$ percentiles) of the lymphocyte subset analyzed unless otherwise stated. Statistical differences between the two cohorts was determined by Mann-Whitney $U$ test while age-related changes in lymphocyte subset within cohorts was analyzed using Friedman test with post-hoc Dunns test for multiple comparisons. Statistically significant $p$-values of $\leq 0.05$ are in bold

malaria-endemic regions [2,27]. Alterations in B-cell homeostasis $[9,11]$, and longevity, quantity and quality of humoral responses based on age and malaria transmission dynamics have previously been reported in children $[2,3,27]$. However, it is unknown what the impact of early differential exposure to P. falciparum on infant B cell development. In this study, the development of B cell subsets was investigated in infants followed through 24 months of age from geographically proximate regions of Kenya that experienced divergent $P$. falciparum

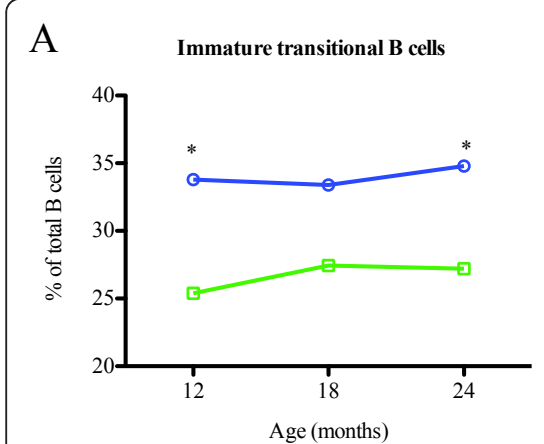

$\mathrm{D}$

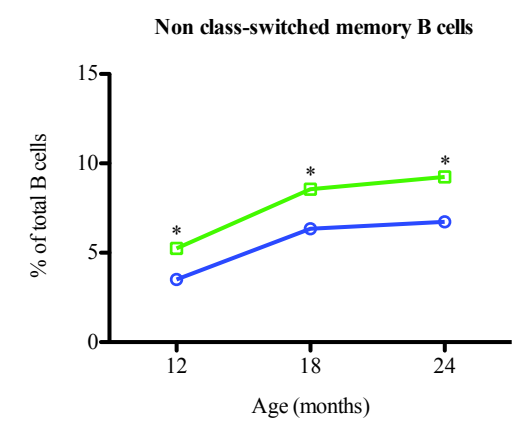

B

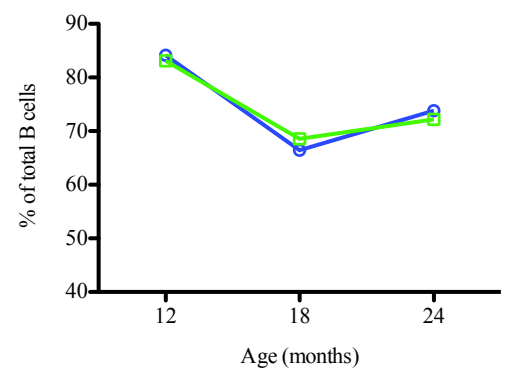

E

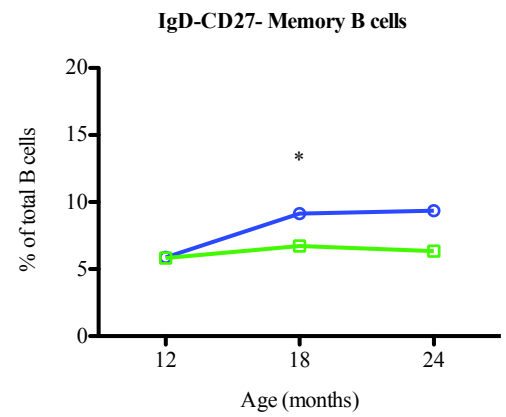

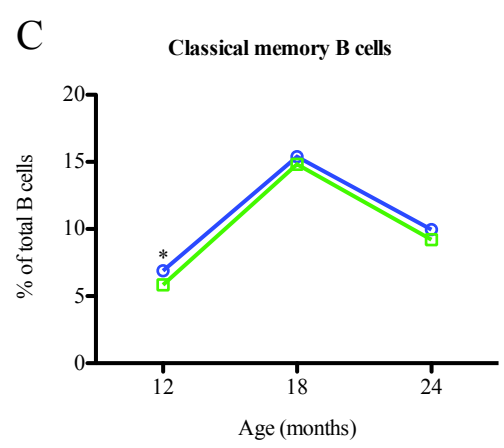

Figure 2 Changes in B cell subsets in infants from Kisumu and Nandi. Panels a-e are the different B cell subsets as determined by flow cytometry as described in Figure 3 and relative frequencies are shown. The different B cell subsets are expressed as a percentage of total CD19 + B cells for both Kisumu and Nandi infants. The circles and blue lines represent Kisumu infants while the squares with green lines represent Nandi infants. Statistical significance in continuous variables between the two cohorts was measured by Mann-Whitney $U$ test while age-related change within the cohorts was measured using Friedman test with a Dunns post-hoc test for multiple comparisons. The asterisk $\left(^{*}\right)$ denotes significant $p$-values $\leq 0.05$. 


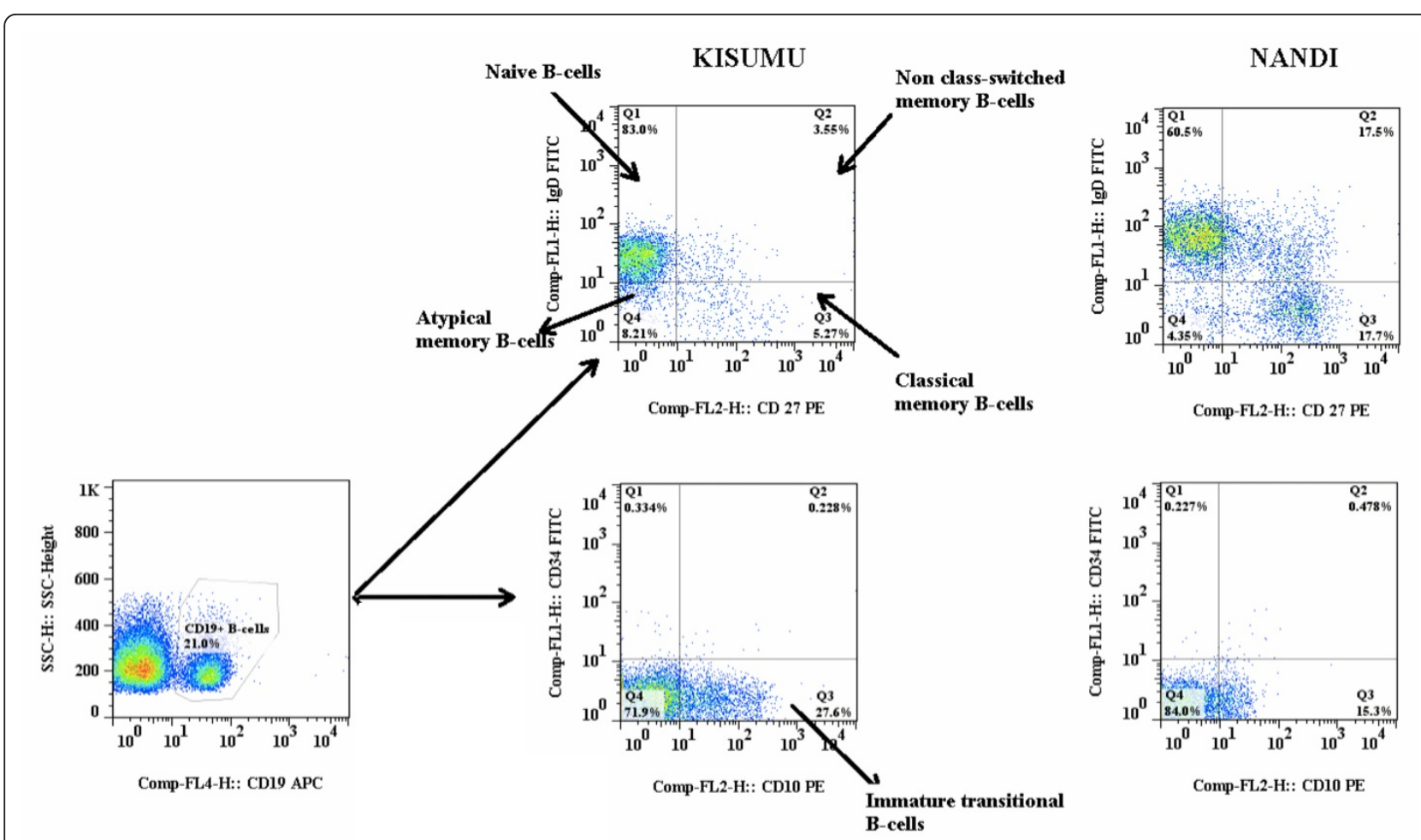

Figure 3 A representative multi-color flow cytometry gating strategy to quantify different B cell subsets in Kisumu and Nandi infants. The B cell subsets FACS plots are of a representative Kisumu and Nandi infant. Within the live CD19+ B cell gate, the B cell subsets were discriminated as follows: immature transitional B cells (CD19+CD10+CD34-), classical naive B cells (CD19+lgD+CD27-), classical memory cells (CD19+lgD-CD27+), non class-switched memory B cells (CD19+lgD+CD27+) and CD19+lgD-CD27- B cells.

transmission dynamics. Infants from the malaria-endemic area had higher overall numbers of CD19+ B cells but reduced populations of circulating IgD+CD27+ memory $\mathrm{B}$ cells and expanded populations of CD10+CD34- immature transitional B cells at all ages relative to infants living in an area with unstable malaria transmission. These data suggest that early exposure to $P$. falciparum infection results in dysregulation of the development of B cell subsets in infants.

Increased frequency and absolute numbers of CD19+ B cells in infants from malaria-endemic region relative to those from an area with unstable malaria transmission at all ages examined suggests that early age or even prenatal exposure to $P$. falciparum infection results in the expansion of the B cell compartment. The expansion of the immature transitional B cells in the peripheral blood observed in this study as well as previously reported during acute clinical malaria in infants [9], could result in increases in the total CD19+ population. Moreover, the P. falciparum erythrocyte membrane proteins 1 (PfEMP1) is a polyclonal B cell activator [28] and could potentially drive expansion of $B$ cells. Overall, these data suggest that impaired antibody responses common in infants from malaria-endemic regions is not due to decline in the frequency of total CD19+ B cells.
Previous studies of individuals with HIV [25], acute clinical malaria [9] systemic lupus erythematosus [29] and X-linked lymphoproliferative disease [30] have found an expansion of immature transitional B cells characterized by expression of CD10. These cells lack CD34 expression [9] and have expression of IL-7 [25] as well as CD24 and CD38 [29,30]. In this study, there was an expansion of this sub-population of immature transitional B cells in infants from Kisumu relative to Nandi at all ages examined. Expansion of transitional B cell populations correlated with impaired humoral immunity [30] thus suggesting the expansion of this population in infants from a malaria-endemic area could contribute to impaired humoral immunity. However, it should be noted that consistent with previous studies, both cohorts of infants had higher levels of transitional B cells than observed in adult counterparts [30].

There is some controversy over whether CD19+IgD+ $\mathrm{CD} 27+\mathrm{B}$ cells in peripheral circulation represent circulating marginal zone B cells[4] or non-class switched memory $B$ cells [31]. It is clear however that this B cell subset is present in the peripheral blood of infants and increases with age [5] and loss of CD19+IgD+CD27+ B cells is observed in pediatric HIV infection [13]. A decline in the frequency 
of IgD +CD27+ memory B cells was observed in circulation of infants from malaria-endemic regions relative to those from an area with unstable malaria transmission at all ages. Although the immunological pathways that orchestrate the depletion of this subset in infants from malaria-endemic region is unknown, splenectomy has been associated with reduced peripheral circulation of this subset in autoimmune patients [32]. Interestingly, $P$. falciparum infection has been shown to disrupt splenic architecture [33], and thus, may interfere with peripheral homeostasis of this B cell subset. Early exposure to P. falciparum may interfere with splenic development and/or disrupt splenic architecture in infants from malaria-endemic region, which could be one possible explanation for the diminution of CD19 $+\mathrm{IgD}+\mathrm{CD} 27+\mathrm{B}$ cells observed in the cohort of infants from Kisumu. Moreover, since this subset produce poly-reactive IgM important in innate immunity against bacterial and viral pathogens [4], the early depletion of this population may result in increased susceptibility to bacterial or viral infections, and reduced efficacy of pneumococcal vaccines in infants from malaria-endemic regions $[34,35]$. The agerelated increase in the frequency of this subset in both cohorts observed is consistent with previous studies showing an age-dependent increase in this B cell subset in infants [4].

There were several limitations of this study. First, since infants were enrolled over a three-month period of time changes in malaria transmission could have occurred. However, we analysed samples from both sites every week over the three-month period to minimize any differences that time of year would have on the results. In addition, while there are well-documented differences in malaria transmission between Kisumu and Nandi, it was not possible to generate an accurate record of the number of malaria infections in the infants in our cohort over the period of observation. In rural areas in Kisumu, infants can be treated at home with anti-malarial drugs bought from local shops. Home treatment could reduce measurable parasitaemia. Because only a monthly followup was available in the first year, some episodes of malaria could be missed. In addition, the instability of antibody responses to malaria [3] in infancy prevented using detection of malaria antibody as a surrogate for malaria infections. Finally, it would be ideal to have a more elaborate B cell phenotyping panel, but at the time of this study, only a three-colour analytic flow cytometer was available for analysis in Kenya. For example, while an elevated frequency of CD19 ${ }^{+}$IgD-CD27- B cells was noted in infants from Kisumu relative to Nandi, because this population includes both immature transitional $\mathrm{B}$ cell subset (IgD-CD27-CD10+) as well as the atypical exhausted memory cells, the significance of this observation cannot be determined.

\section{Conclusions}

In conclusion, these results demonstrated that there were profound differences in B cell subsets in infants from geographically proximate regions with divergent malaria exposure that were independent of the maturation of the immune system in infants. These data further provide evidence that impaired humoral immune response in infants living in malaria endemic regions may be a result of multifactorial factors, including suppression of IgD+CD27+ memory B cells, and expansion of immature transitional $B$ cells. Future work is needed to elucidate the effects of early expansion of immature transitional B cells and depletion of IgD + CD27 + memory B cells on infants functional immunity and whether malaria control programmes targeting pregnant women and their infants can preserve $B$ cell development in infants from malaria-endemic regions.

\section{Additional material}

Additional file 1: Absolute lymphocyte counts for the different B cell subpopulations in infants from areas with divergent malaria exposure according to age.

\section{Acknowledgements}

We are grateful to the study participants parents and guardians for allowing their children to participate in this study. We thank the study medical staff at Chulaimbo and Mosoriot Sub-District hospitals. We are also grateful to the field coordinators especially Otiledon Opinya, John Oyombe and John Ogone. This work was supported by National Institutes of Health $(\mathrm{NIH})$ grant $\mathrm{NIH} \mathrm{R01-CA102667} \mathrm{(RR).} \mathrm{This} \mathrm{work} \mathrm{was} \mathrm{published} \mathrm{with} \mathrm{the} \mathrm{permission} \mathrm{of} \mathrm{the}$ Director Kenya Medical Research Institute (KEMRI).

\section{Author details}

${ }^{1}$ Maseno University, Maseno, Kenya. ${ }^{2}$ Center for Global Health Research, Kenya Medical Research Institute, Kisumu, Kenya. ${ }^{3}$ SUNY Upstate Medical University, Syracuse, NY, USA. ${ }^{4}$ Médecins Sans Frontières-Operational Centre Amsterdam, Amsterdam, The Netherlands.

\section{Authors' contributions}

ASA participated in study design, carried out the cell isolation, cell analysis and drafted the manuscript. ER participated in the design and coordination of the study and draft of manuscript. PSO, SO and NF participated in recruitment, FCF, ELISA and PCR analysis. WGZOJ and CO carried out the statistical analysis and drafted the manuscript. RR conceived of the study, and participated in its design and coordination and drafted the manuscript. All authors read and approved the final manuscript.

\section{Competing interests}

The authors do not have any commercial or other association that might pose a conflict of interest.

Received: 30 July 2011 Accepted: 13 December 2011

Published: 13 December 2011

\section{References}

1. Moormann AM: How might infant and paediatric immune responses influence malaria vaccine efficacy? Parasite Immunol 2009, 31:547-559.

2. Chelimo K, Ofulla AV, Narum DL, Kazura JW, Lanar DE, John CC: Antibodies to Plasmodium falciparum antigens vary by age and antigen in children in a malaria-holoendemic area of Kenya. Pediatr Infect Dis J 2005, 24:680-684. 
3. Kinyanjui SM, Conway DJ, Lanar DE, Marsh K: IgG antibody responses to Plasmodium falciparum merozoite antigens in Kenyan children have a short half-life. Malar J 2007, 6:82

4. Weill JC, Weller S, Reynaud CA: Human marginal zone B cells. Annu Rev Immunol 2009, 27:267-285.

5. Weller S, Mamani-Matsuda M, Picard C, Cordier C, Lecoeuche D, Gauthier F, Weill JC, Reynaud CA: Somatic diversification in the absence of antigendriven responses is the hallmark of the $\lg M+\lg D+C D 27+B$ cell repertoire in infants. J Exp Med 2008, 205:1331-1342.

6. Kruetzmann S, Rosado MM, Weber H, Germing U, Tournilhac O, Peter HH, Berner R, Peters A, Boehm T, Plebani A, Quinti I, Carsetti R: Human immunoglobulin M memory B cells controlling Streptococcus pneumoniae infections are generated in the spleen. J Exp Med 2003, 197:939-945.

7. Capolunghi F, Cascioli S, Giorda E, Rosado MM, Plebani A, Auriti C, Seganti G, Zuntini R, Ferrari S, Cagliuso M, Quinti I, Carsetti R: CpG drives human transitional $B$ cells to terminal differentiation and production of natural antibodies. J Immunol 2008, 180:800-808.

8. Moir S, Ho J, Malaspina A, Wang W, DiPoto AC, O'Shea MA, Roby G, Kottilil S, Arthos J, Proschan MA, Chun TK, Fauci AS: Evidence for HIVassociated $B$ cell exhaustion in a dysfunctional memory $B$ cell compartment in HIV-infected viremic individuals. J Exp Med 2008, 205:1797-1805.

9. Asito AS, Moormann AM, Kiprotich C, Ng'ang'a ZW, Ploutz-Snyder R, Rochford R: Alterations on peripheral $B$ cell subsets following an acute uncomplicated clinical malaria infection in children. Malar J 2008, 7:238.

10. Dorfman JR, Bejon P, Ndungu FM, Langhorne J, Kortok MM, Lowe BS, Mwangi TW, Williams TN, Marsh K: B cell memory to 3 Plasmodium falciparum blood-stage antigens in a malaria-endemic area. $J$ Infect Dis 2005, 191:1623-1630

11. Weiss GE, Crompton PD, Li S, Walsh LA, Moir S, Traore B, Kayentao K, Ongoiba A, Doumbo OK, Pierce SK: Atypical memory B cells are greatly expanded in individuals living in a malaria-endemic area. $J$ Immunol 2009, 183:2176-2182.

12. Weiss GE, Clark EH, Li S, Traore B, Kayentao K, Ongoiba A, Hernandez JN, Doumbo OK, Pierce SK, Branch OH, Crompton PD: A positive correlation between atypical memory $B$ cells and Plasmodium falciparum transmission intensity in cross-sectional studies in Peru and Mali. PLOS One 2011, 6:e15983.

13. Jacobsen MC, Thiebaut R, Fisher C, Sefe D, Clapson M, Klein N, Baxendale HE: Pediatric human immunodeficiency virus infection and circulating IgD+ memory B cells. J Infect Dis 2008, 198:481-485.

14. Bockstal V, Geurts N, Magez S: Acute disruption of bone marrow b lymphopoiesis and apoptosis of transitional and marginal zone b cells in the spleen following a blood-stage Plasmodium chabaudi infection in mice. J Parasitol Res 2011, 2011:534697.

15. Beier JC, Oster CN, Onyango FK, Bales JD, Sherwood JA, Perkins PV Chumo DK, Koech DV, Whitmire RE, Roberts CR: Plasmodium falciparum incidence relative to entomologic inoculation rates at a site proposed for testing malaria vaccines in western Kenya. AmJTrop Med Hyg 1994, 50:529-536.

16. Ernst KC, Adoka SO, Kowuor DO, Wilson ML, John CC: Malaria hotspot areas in a highland Kenya site are consistent in epidemic and nonepidemic years and are associated with ecological factors. Malar J 2006, 5:78.

17. Ndenga B, Githeko A, Omukunda E, Munyekenye G, Atieli H, Wamai $P$, Mbogo C, Minakawa N, Zhou G, Yan G: Population dynamics of malaria vectors in western Kenya highlands. J Med Entomol 2006, 43:200-206.

18. Piriou E, Asito AS, Sumba PO, Moormann AM, Ploutz-Snyder R, Rochford R: Early age of primary EBV infection results in poorly controlled viral infection in infants from Western Kenya: clues to the etiology of endemic Burkitt's lymphoma. J Inf Disease.

19. Menge DM, Ernst KC, Vulule JM, Zimmerman PA, Guo H, John CC: Microscopy underestimates the frequency of Plasmodium falciparum infection in symptomatic individuals in a low transmission highland area. AmJTrop Med Hyg 2008, 79:173-177.

20. Rainey JJ, Mwanda WO, Wairiumu P, Moormann AM, Wilson ML, Rochford R: Spatial distribution of Burkitt's lymphoma in Kenya and association with malaria risk. Trop Med Int Health 2007, 12:936-943.

21. Moormann AM, Chelimo K, Sumba OP, Lutzke ML, Ploutz-Snyder R, Newton D, Kazura J, Rochford R: Exposure to holoendemic malaria results in elevated Epstein-Barr virus loads in children. J Infect Dis 2005, 191:1233-1238

22. Hermsen CC, Telgt DS, Linders EH, van de Locht LA, Eling WM, Mensink EJ Sauerwein RW: Detection of Plasmodium falciparum malaria parasites in vivo by real- time quantitative PCR. Mol Biochem Parasitol 2001, 118:247-251.

23. Osugi Y, Hara J, Kurahashi H, Sakata N, Inoue M, Yumura-Yagi K, Kawa-Ha K, Okada S, Tawa A: Age-related changes in surface antigens on peripheral lymphocytes of healthy children. Clin Exp Immunol 1995, 100:543-548.

24. Kassu A, Tsegaye A, Petros B, Wolday D, Hailu E, Tilahun T, Hailu B, Roos MT, Fontanet AL, Hamann D, De Wit TF: Distribution of lymphocyte subsets in healthy human immunodeficiency virus-negative adult Ethiopians from two geographic locales. Clin Diagn Lab Immunol 2001, 8:1171-1176.

25. Malaspina A, Moir S, Ho J, Wang W, Howell ML, O'Shea MA, Roby GA, Rehm CA, Mican JM, Chun TW, Fauci AS: Appearance of immature/ transitional B cells in HIV-infected individuals with advanced disease: correlation with increased IL-7. Proc Natl Acad Sci USA 2006, 103:2262-2267.

26. Jacobi AM, Reiter K, Mackay M, Aranow C, Hiepe F, Radbruch A, Hansen A, Burmester GR, Diamond B, Lipsky PE, Dorner T: Activated memory B cell subsets correlate with disease activity in systemic lupus erythematosus: delineation by expression of CD27, IgD, and CD95. Arthritis Rheum 2008, 58:1762-1773.

27. Scott S, Cumberland P, Shulman CE, Cousens S, Cohen BJ, Brown DW, Bulmer JN, Dorman EK, Kawuondo K, Marsh K, Cutts F: Neonatal measles immunity in rural Kenya: the influence of HIV and placental malaria infections on placental transfer of antibodies and levels of antibody in maternal and cord serum samples. J Infect Dis 2005, 191:1854-1860.

28. Donati D, Mok B, Chene A, Xu H, Thangarajh M, Glas R, Chen Q Wahlgren $M$, Bejarano MT: Increased B cell survival and preferential activation of the memory compartment by a malaria polyclonal $B$ cell activator. J Immunol 2006, 177:3035-3044.

29. Sims GP, Ettinger R, Shirota Y, Yarboro CH, Illei GG, Lipsky PE: Identification and characterization of circulating human transitional B cells. Blood 2005, 105:4390-4398

30. Cuss AK, Avery DT, Cannons JL, Yu LJ, Nichols KE, Shaw PJ, Tangye SG: Expansion of functionally immature transitional $B$ cells is associated with human-immunodeficient states characterized by impaired humoral immunity. J Immunol 2006, 176:1506-1516.

31. Klein U, Rajewsky K, Kuppers R: Human immunoglobulin (lg)M+lgD +peripheral blood B cells expressing the CD27 cell surface antigen carry somatically mutated variable region genes: CD27 as a general marker for somatically mutated (memory) B cells. J Exp Med 1998, 188:1679-1689.

32. Martinez-Gamboa L, Mei H, Loddenkemper C, Ballmer B, Hansen A, Lipsky PE, Emmerich F, Radbruch A, Salama A, Dorner T: Role of the spleen in peripheral memory B-cell homeostasis in patients with autoimmune thrombocytopenia purpura. Clin Immunol 2009, 130:199-212.

33. Urban BC, Hien TT, Day NP, Phu NH, Roberts R, Pongponratn E, Jones M, Mai NT, Bethell D, Turner GD, Ferguson D, White NJ, Roberts DJ: Fatal Plasmodium falciparum malaria causes specific patterns of splenic architectural disorganization. Infect Immun 2005, 73:1986-1994.

34. Usen S, Milligan P, Ethevenaux C, Greenwood B, Mulholland K: Effect of fever on the serum antibody response of Gambian children to Haemophilus influenzae type b conjugate vaccine. Pediatr Infect Dis $J$ 2000, 19:444-449.

35. Cutts FT, Zaman SM, Enwere G, Jaffar S, Levine OS, Okoko JB, Oluwalana C, Vaughan A, Obaro SK, Leach A, McAdam KP, Biney E, Saaka M, Onwuchekwa U, Yallop F, Pierce NF, Greenwood BM, Adegbola RA, Gambian Pneumococcal Vaccine Trial Group: Efficacy of nine-valent pneumococcal conjugate vaccine against pneumonia and invasive pneumococcal disease in The Gambia: randomised, double-blind, placebo-controlled trial. Lancet 2005, 365:1139-1146.

doi:10.1186/1475-2875-10-362

Cite this article as: Asito et al:: Suppression of circulating lgD+CD27+ memory $B$ cells in infants living in a malaria-endemic region of Kenya. Malaria Journal 2011 10:362. 